\title{
Meaning and reference: the interpretation of general terms
}

\author{
by Ross Charnock
}

This is the second of two articles adapted from a lecture given to the Statute Law Society at the Institute of Advanced Legal Studies on October 1, 2007. The first concerned direct reference to individuals.

\section{INTRODUCTION}

$\mathrm{R}$ eference to classes and natural kinds is necessarily more complex than reference to specific objects or ndividuals, not just because there is no direct reference to anything in particular, but also because reference is made to concepts rather than to empirical objects. Both lawyers and linguists have found definitions based on fixed criteria to be unsatisfactory. The interpretation of general terms has been considered problematic since at least Heydon's case, 76 ER 637 (1584).

In linguistics, related concepts are commonly distinguished through an analysis of semantic features. Thus chairs are distinguished from armchairs or stools through the presence or absence of "backs" and "arms", while young fur seals, young knights, university graduates and unmarried men, all referred to as "bachelors", have in common markers like "animate", "human", "male" or "lowest degree" (Katz and Fodor, 1963). Such markers supply an approximate definition of a given word. For legal purposes, the relevant common features play an obvious role in ejusdem generis interpretation. However, they are rarely sufficient for purposes of definition. (The Pope is both male and unmarried, but he is probably not a "bachelor".)

In order to reduce reliance on personal intuition, and to ensure objectivity, lawyers often give more and more elaborate definitions, multiplying the applicable criteria as necessary. It is one of the more important functions of the higher courts to adjust such definitions, where possible (but no more than necessary), in order to take account of the new problems.

Unfortunately, as was pointed out by Waismann (Verification, 1951), such definitions can never be complete. The reason is that things are associated with an indefinite number of semantic features, some of which have not yet been noticed, while others may never be noticed by anyone. The examples Waismann proposes are admittedly somewhat extreme. They involve, among other things, a new kind of gold which emits radiation, or cats which speak Latin. He admits that such things do not occur in real life, but answers (1951, 120): “[...] We can never exclude altogether the possibility of some unforeseen situation arising in which we shall have to modify our definition." As it is not possible to envisage all possible situations, or every new discovery, all definitions must remain uncertain and unreliable. Waismann concludes (1951: 123): "Every definition stretches into an open horizon. Can you foresee all the facts which would turn a putative fact into a delusion?" This was his problem of open texture.

It is often assumed that the concepts associated with general terms must have at least one feature in common. This claim was made explicitly by Lord Atkin in Donoghue v Stevenson [1932] AC 562: "And yet the duty which is common to all cases where liability is established must logically be based upon some element common to the cases where it is found to exist." This idea seems initially plausible, yet it is logically mistaken, as was pointed out by Wittgenstein in his discussion of family resemblances (Philosophical investigations 1953, para 66): “Consider for example the proceedings that we call 'games'. I mean board-games, card-games, ball-games, Olympic games, and so on. [...] if you look at them you will not see something that is common to all, but similarities, relationships, and a whole series of them at that."

Given that the number of possible semantic features is indeterminate, no member of a family can possess them all. It follows that no single feature will necessarily be shared by all the members. Wittgenstein considers the assumption that different games have in common the disjunction of their common properties, as "naive". This corresponds 
well with Lord Macmillan's prescient warning in Donoghue: "the categories of negligence are never closed".

\section{"TRUE AND CORRECT" MEANINGS}

On the traditional view, the extension of a general term, the set of things to which the term applies, is defined by reference to fixed criteria. However the extension cannot exhaust the meaning of a given expression, as then different expressions used to refer to identical sets would be synonymous. Quine gave the example of a "creature with a heart", which on the purely referential view would have the same meaning as "creature with a kidney". Although the two expressions have the same extension, the connotation or intended meaning may vary. This shows that there is a fundamental distinction between meaning and reference, also referred to in semantics as extension vs. intension (or in Fregean terms, as Sinn vs. Bedeutung). On this view, the intension is the subjective element of meaning, a private mental entity rather than a shared, public property.

Putnam (Is semantics possible?, 1970) rejects the traditional view, pointing out that criterial definitions falsify the properties of words. He reminds us that members of a natural kind may have abnormal members ("green lemons" or "three-legged tigers"). He points out (The meaning of meaning, 1975) that while the extension can only be a set of things, a "yes/no" object, a tree for example is in fact a fuzzy concept.

It is generally accepted that two terms can have same extension yet differ in intension. Putnam (Are meanings in the head?, 1975) goes further, establishing that the converse is also true. In a celebrated thought experiment, he supposes a twin earth (Twearth), exactly like Earth except that water is not $\mathrm{H}_{2} \mathrm{O}$ but XYZ. A spaceship from Earth will report "On Twearth the word 'water' means 'XYZ", Symmetrically, a Twearthian spaceship will report "On earth 'water' means ' $\mathrm{H}_{2} \mathrm{O}$ '”. So far this is just a question of ambiguity, the word having one extension on Earth and another on Twearth. However, if relations with Twearth had taken place in 1750, when there was no knowledge of chemistry on either earth, then no one would have known that the word "water" was ambiguous. Yet the extensions were in fact different, as we now know.

Putnam goes on to point out that even on Earth at the present time, pots and pans may be made out of "molybdenum" rather than aluminium. To non-experts, these two elements appear to be indistinguishable. For ordinary people using these words, there is therefore no difference in psychological state, yet the extensions of the terms still differ. Putnam himself famously claimed not to know the difference between an elm and a beech tree. Thus for him the concepts were identical, even though the words in fact have different extensions. The inevitable conclusion is that meaning cannot be fixed by description and must vary according to the knowledge and beliefs of the speaker (or the legislature).

This explains why references to dictionary definitions in legal judgments are rarely dispositive. Take the definition of "male" given by Lord Hope in Bellinger v Bellinger [2003] AC 21: "The definition of 'male' in the New Shorter Oxford English Dictionary (1993) tells us that its primary meaning when used as an adjective is 'of, pertaining to, or designating the sex which can beget offspring." If this capacity was made obligatory, not only would it exclude transsexual marriage, it would also invalidate numerous more conventional marriages. Note also the definition of “appropriates" cited by Lord Lowry (dissenting) in DPP v Gomez [1993] AC 442: “The primary dictionary meaning is 'take possession of, or take to oneself, especially without authority', and that is in my opinion the meaning which the word bears in section1(1) [of the Theft Act 1968]." Not only did this fail to dispose of the case, it was actually rejected by the majority.

\section{STEREOTYPES}

Putnam (1970) therefore rejects definitions of natural kinds which depend on conjunctions of properties. While he agrees that lemons are usually yellow and taste bitter, he refuses to accept that all lemons must necessarily have those properties. On the contrary, "to say that something is a lemon is to say that it belongs to a natural kind whose normal members have certain properties; but not to say that it necessarily has those properties itself." His conclusion is that: "There are no analytic truths of the form 'Every lemon has p'. We remember that, although 'Jif' lemons were plastic, they were still called 'lemons'. Similarly, 'water' cannot be defined as $\mathrm{H}_{2} \mathrm{O}$, as that word is more usually used to refer to what is found in lakes or what comes out of the tap. It is an empirical question how we will refer to pencils, if in the future we discover that they are (and have always been) organisms, or to 'cats' if they turn out to be robots remotely controlled from Mars".

More prosaically, although a cup is distinguished from a beaker through the presence of a handle, we do not know in advance whether we will still call it by that name if its handle falls off.

Putnam (1975) therefore developed a theory of reference to natural kinds in terms of 'stereotypes'. The stereotype corresponds to the conventional idea of the kind under consideration (stereotypical tigers are striped, and stereotypical gold is yellow); but the basic features evoked are never analytically necessary. Thus albino tigers need not be considered logically contradictory, and we can accept without incoherence that chemically pure gold is in fact white. Clearly, stereotypes are reasonably accurate for normal purposes; otherwise there would be no communication. 


\section{Stereotypes in the law}

The concept of stereotypes was introduced as an account of everyday communication. However, they also feature in legal argument. In Mandla v Dowell Lee CA [1982] 3 WLR 932, for example, a Sikh claimed that the refusal to admit his son to a private school unless he wore the school uniform (instead of his turban) constituted indirect racial discrimination under the RRA 1976. The CA took a traditional approach, and held unanimously that the Sikhs did not constitute a "race" as defined in the OED. Mandla's claim was therefore rejected. It was recognised that the term 'race' was problematic. Indeed, some scientists and social anthropologists denied that it had any meaning at all. (As Parliament must have meant something, Lord Kerr considered that the concept should be judicially defined by reference to colour.)

In the RRA 1976, an alternative definition is given in terms of "ethnic origin". However, this term was also problematic. Denning LJ adopted the definition given in the Concise Oxford Dictionary, 1934: "That was the meaning given which I - acquiring my vocabulary in 1934 - have always myself attached to the word 'ethnic'. It is, to my mind, the correct meaning. It means 'pertaining to race'." The definitions given in more recent dictionaries were even less helpful. The latest edition of the OED gave: "foreign or exotic; un-American or plain quaint", while the Collins English Dictionary 1979 unhelpfully gave "Bosnian ethnic dances" as an illustration of the relevant concept. The CA determined that the term should not be taken to apply to any characteristic which could be assumed or rejected as a matter of choice, Oliver LJ pointing out that: "No one, for instance, in ordinary speech, would describe a member of the Church of England or the Conservative Party as a member of an ethnic group."

However, when the case reached the HL the following year ([1983] 2 AC 548), their Lordships adopted a very different approach to definition. Lord Fraser of Tullybelton proposed a number of "essential conditions" for consideration as a race (a long shared history, a cultural tradition, a common geographical origin, a common language, a common literature, a common religion and being a minority within a larger community). However these conditions were not considered to be necessary. They were thought of instead as part of the relevant stereotype. Thus, for the purposes of the Act, a group defined by reference to "enough of these characteristics" should be accepted as a "race". Lord Templeman took a similar approach to the definition of "ethnic": "[...] a group of persons defined by reference to ethnic origins must possess some of the characteristics of a race [...]. The evidence shows that the Sikhs satisfy these tests. They are more than a religious sect, they are almost a race and almost a nation." Having adopted a different approach to definition, the Lords unanimously reversed the decision given by the CA.

\section{PROTOTYPES}

An alternative approach to the interpretation of general terms is found in the theory of prototypes (Rosch, Prototype classification and logical classification, 1983). In this cognitive model of understanding, the idea of definition is rejected altogether. Instead, the meaning is supplied through examples. The best instances of the type referred to by a given general term are said to be prototypical, while others are classed as peripheral. In this theory, as with stereotypes, there is no true or false test for the use of a word. Rather, examples are evaluated as more or less appropriate. This model has proved productive in psycholinguistics, and has led to testable hypotheses concerning language acquisition. It works well as an account of natural language understanding, to the extent that we have shared ideas of best instances. It is generally agreed, for example, that an oak is a prototypical tree, while (in England and America) a robin may be the best instance of a bird. Although an ostrich is technically a bird, speakers agree that it is a less central example. For particular purposes, whales may be classed as fish, or tomatoes as vegetables.

Prototype theory was originally applied to nouns, especially natural kind words. However, the notion of "core meaning" also extends to verbs. Thus the verb "to break" is thought to be used more prototypically in "breaking a cup" than in "a wave breaking." In the same way, the core meaning of "to run" is more likely to be associated with running a race than with running a risk (or a company).

\section{Prototypes in legal adjudication}

Legal adjudication is often based on prototypical reasoning. A convenient example is found in Nix v Heddon 149 US 304 (1893). The American Tariff Act 1883 imposed a duty on "vegetables" at "ten per centum ad valorem". When the authorities attempted to charge the 10 per cent duty on tomatoes, it was pointed out, reasonably enough, that a tomato was not a vegetable but a fruit. At trial, counsel for the plaintiff read in evidence definitions of the words "fruit" "vegetables" and "tomato" from Webster's Dictionary, and called witnesses to show that the words had no special meaning in trade or commerce, different from those read. The defendant's counsel then read the definitions of the words "pea”, "egg plant", "cucumber", "squash" and "pepper". No other evidence was offered by either party.

Justice Gray - distinguished author of Nature and sources of the law, 1909, and of the minority opinion in Riggs $\mathrm{V}$ Palmer 22 N.E. 188 (1889) - nevertheless pointed out that: "In the common language of the people [...] all these are vegetables, which are [...] like potatoes, carrots, parsnips, [...] usually served at dinner with the fish or meats [...], and not, like fruits generally, as dessert.". 
While stereotypes and prototypes are alternative accounts of the cognitive processes involved in natural language understanding, they are not mutually exclusive. Indeed, dictionary definitions commonly include both criterial definitions and examples. Further, an intuition based on prototypes may be reinforced or justified where necessary by reference to stereotypical features, as is frequently observed in legal argument.

In United Biscuits $v$ Customs and Excise VAT Tribunal 91/160 (1991), the Tribunal had to decide whether "Jaffa cakes" were in fact cakes (and therefore zero rated for VAT). Chocolate-covered biscuits, as "luxury items", would be liable for the normal rate. As the products in question were not prototypical cakes, the court had to decide whether they should nevertheless be accepted as peripheral examples.

However, although the case depended mainly on the judge's intuitive recognition of the relevant kind, legal argument was based not on prototypes, but on semantic features. The customs authorities argued that Jaffa cakes are the size of biscuits, packaged as biscuits, eaten with fingers like biscuits, and kept on the biscuit shelf at the supermarket. United Biscuits pointed out other unsuspected characteristics, more favourable to their case (a biscuit goes soft when stale, whereas a Jaffa cake, like a cake, goes hard). The company managed to convince the judge that the criterion of size was of secondary importance, apparently by offering him a specially prepared 12-inch Jaffa cake. No doubt HM Customs lacked the facilities to rebut this argument with a 12-inch chocolate-covered biscuit. Potter QC concluded that: "Jaffa cakes have sufficient characteristics of cakes to qualify as cakes within the meaning of item number 1 in group 1 of the fifth schedule. If it be relevant, I also determine that the Jaffa cakes are not biscuits."

\section{Open texture}

Hart (The Concept of Law, 1961), introduced his concept of 'open texture' as follows: "There will indeed be plain cases constantly recurring in similar contexts to which general expressions are clearly applicable ('If anything is a vehicle a motor-car is one), but there will also be cases where it is not clear whether they apply or not. (Does 'vehicle' used here include bicycles, airplanes, rollerskates?)" (Hart 1961: 126).

Although the linguistic problem figures here almost as an afterthought, in parentheses, it appears to correspond closely to the theory of prototypes. The "motor car" is prototypical, whereas the other examples of "vehicles" are peripheral, or in Hart's terms, part of the penumbra associated with the concept. Yet Hart refers explicitly in his famous endnotes to Waismann, whose theory of open texture was related not to vagueness, or to peripheral features, but rather to the indeterminacy of the central concepts themselves. Hart may have failed to appreciate the problems of indeterminacy raised by Waismann, preferring instead to suppose that judicial discretion is required only in "hard cases". Alternatively, he may be thought to have invented the notion of prototypes more than 20 years before the term was introduced into linguistics.

The fact remains that Hart raised new theoretical problems concerning the semantics of general terms in the law, some of which actually occurred in practice. The definition of "vehicle" was the subject of Garner v Burr [1951] $1 \mathrm{~KB} 31$, included in Hart's first reading list for his Oxford law students. A farmer had strapped wheels to his chicken coop and towed it along the road with his tractor, contrary to a rule in the Road Traffic Act 1930, forbidding the use of vehicles without rubber tyres on the public highway. When prosecuted, his successful defence was that his chicken coop was not a vehicle. On appeal, Goddard CJ accepted that a "vehicle" is primarily a means of conveyance with wheels or runners used for the carriage of persons or goods, and further that nothing was being carried in the poultry shed at the relevant time. He nevertheless held that an offence had been committed, and that the magistrates "ought to have found that this poultry shed was a vehicle within the meaning of section 1 of the Road Traffic Act of 1930".

Chicken coops do not correspond to any stereotypical definition of "vehicle"; nor can they realistically be thought of as a peripheral example of the concept. This kind of interpretation goes far beyond any periphery (perhaps even beyond the Staines by-pass). Such understanding depends crucially on specific purposes in particular situations, as in the contextualist theory of "what is said".

\section{CONTEXTUALISM}

Meanings are said to be ambiguous where contextual knowledge is required to supply the deictic references and to select the appropriate sense. Where this information is unavailable, possibly because the words must be interpreted in a context which was never envisaged by the speaker, the meaning is pragmatically indeterminate. This is often the case in statute construction, as with 'appropriates' in theft (Lawrence $V$ Metropolitan Police Commissioner [1972] AC 626 or DPP $v$ Gomez [1993] AC 442), or even "entry" in $R_{v}$ Collins [1972] 2 All ER 1105. The role of the background context in semantic interpretation was debated at length in a series of American cases concerning the interpretation of a Federal law providing for severe minimum sentences where a firearm is "used or carried" during the commission of "any felony" related to drugs (18 U.S.C. B 924(c)(1)). In Smith v US 508 U.S. 223 (1993), it appeared that, after some negotiation with an undercover police officer, Smith had misguidedly offered to trade his automatic weapon for four ounces of cocaine. The Supreme Court had to decide whether this constituted "use" of the firearm. 
Justice O'Connor admitted that the relevant phrase would normally evoke an image of "use for shooting". However, having considered the definitions given in a number of dictionaries, including Webster's ("to convert to one's service" or "to employ") she considered that other uses could not be excluded, and therefore accepted "use for barter" as within the statute. The minimum sentence, in this case 30 years' imprisonment, was therefore imposed. Justice Scalia, dissenting, protested that: "The court does not appear to grasp the distinction between how a word can be used and how it ordinarily is used." He claimed that: "the plain meaning of the word must be drawn from the context in which it is used."

Following this decision, an article was published giving the linguistic perspective on this debate ("Using common sense”, Cunningham/Fillmore, 1995). It was pointed out that the meaning of a word may differ within a single sentence. Thus in: "I use a gun to protect my house, but I've never had to use it", the first occurrence refers to "use for reassurance" while the other is related to "use as a weapon". This insight appeared relevant in Bailey v United States 516 U.S. 137 (1995), in which the same statute was reinterpreted. This time, the accused was said to have "used" a gun by keeping it in the car boot while transporting marijuana. The USSC now found that the statute did not apply, citing in argument Cunningham/Fillmore's invented example. However, in a third case, Muscarello v US 524 US 125 [1998], the accused was found instead to have "carried" the gun in the glove compartment of his car. In support of this interpretation, Justice Breyer cited a statistical analysis of an electronic newspaper corpus: "Random sampling suggests that many, perhaps more than one third, are sentences used to convey the meaning at issue here." He noted, reassuringly, that the Bible refers repeatedly to goods being "carried" on chariots or young asses, and considered that other possible meanings were not relevant. In dissent, Justice Ginsberg wondered pointedly what other meanings may have "showed up some two thirds of the time".

Recurrent difficulties of this kind show that it would be it would be more satisfactory to abandon the assumption that meanings can be fixed by authoritative definition, and to recognise instead the importance of background context in interpretation. On this view, the natural or plain meaning, as observed in context, is no longer taken to be equivalent to "literal meaning". Instead, interpretation is based on "what is said".

\section{Literal meaning and "what is said"}

Traditional theory involves a binary distinction between an invariant semantic meaning, associated with the sentence-type, and a pragmatic, intentional meaning associated with the utterance. Given this distinction, it becomes necessary to show how the communicative intention can be derived from the postulated literal meaning. Grice (1957) famously proposed a set of maxims intended to formalise the principles required for pragmatic interpretation in ordinary conversation. These work well where understanding depends on conversational implicature in specific contexts, for example where an utterance like "It's warm in here" is taken as a request to open the window, or "I have seen that film" as indicating a preference for another.

Unfortunately, this theory cannot be empirically verified. As all utterances are made in specific situations, and as by definition, the context must always have an effect on interpretation, the literal meaning is in practice unobservable. Problems appear with sentences like "Mary has drunk two glasses of wine", or "Odette has three children", which are logically equivalent to "Mary has drunk 'at least' two glasses of wine", or "Odette has 'at least' three children". The understanding that Mary has consumed "only" two glasses, or that Odette has "only" three children must therefore be explained through the machinery of conversational implicature.

Travis (The uses of sense, 1989) proposes a more realistic account, which shows how basic meanings and even truthvalues vary according to context. To take just one of his many examples, a simple affirmative sentence including the natural kind term "milk" may appear true or false on different sayings, according to purpose. Thus, "There is milk in the fridge" will be considered true by someone about to prepare breakfast, if the fridge contains a carton of milk, but false if there is just a puddle of milk on the shelf. However, for someone checking on whether her husband has cleaned the kitchen properly, the opposite would be the case. Neither interpretation could be derived from a putative literal meaning, which would involve something like a fridge full of (wall-to-wall) milk.

In the same way, a sentence like "The water's blue today" would be true for someone admiring the view of a lake in midsummer; yet the same sentence, spoken on the same day, and referring to the water in the very same lake, may well be evaluated differently by someone investigating pollution levels. Again, a literal interpretation would be rejected as self-contradictory, for it is well known that water is not in fact blue, but colourless. In this contextualist model, the semantic meaning ("what is said") depends on the domain of discourse.

On this account of natural understanding, contrary to the judicial tradition, there is no literal meaning, even on an abstract, purely theoretical level. The discourse context does not simply provide a basis for disambiguation, but actually establishes the sense of "what is said". This does not of course exclude recourse to conversational implicature, as a specific pragmatic understanding may unproblematically be derived from the general semantic sense. Thus one sense of "there is milk in the fridge" may implicate an invitation to prepare cornflakes, while the other may carry a suggestion that the fridge should be cleaned again. 
Although English judges often claim to be basing their interpretation on the "literal" meaning of the words, rather than on hypotheses concerning legislative intention, they nevertheless recognise that no understanding is possible without reference to the supposed purpose in the given discourse situation. They even go so far as to speak of the "literal meaning in context". As literal meaning is by definition acontextual, this phrase appears at first sight to be a simple contradiction in terms. However, it should perhaps be interpreted more charitably, as corresponding to the linguistic concept of "what is said". Notice in support of this view that English judges seem to have adopted the word "colour" as a grammatical term, when referring to the importance of context in the interpretation of general terms. In $A G_{v}$ Prince Ernest-Augustus [1957] AC 436, Viscount Simonds stated that "Words, and particularly general words, cannot be read in isolation, their colour and content are derived from their context." Similarly, in Bourne v Norwich Crematorium [1967] 1 All ER 576, Stamp J pointed out that: "English words derive colour from those which surround them."

\section{CONCLUSION - SEMANTICS AND PRECEDENT}

Hart (1961: 126) rejects the popular but simplistic distinction between the "the uncertainties of communication by authoritative example (precedent), and the certainties of communication by authoritative general language (legislation)”. His invented example (1961: 124) is: "Every man and boy must take his hat off when entering a church", as opposed to: "Look, this is the right way to behave on such occasions." Although he is reluctant to accept sceptical claims of radical indeterminacy, he considers the distinction between written rules and common law precedents to be less clear than is commonly assumed, and suggests that the rules given in written statutes may be no more determinate than the instructions implicit in precedents. Hart's parallel between should be taken further.

In prototype theory, the meanings of general terms depend not on definition, but rather on representative examples. Uncertainties are more likely to arise in peripheral cases. The same is true of legal precedents, the application of which depends on the extent to which the case is considered representative, or "in point". In the theory of stereotypes, the sense of general terms depends on generally accepted ideas about which properties or semantic features are fundamental. Just as it is often unclear how precedents should apply in new, unenvisaged contexts, communication is often problematic when words are applied in new ways in new circumstances.

In Waismann's theory of open texture, problems arise where hitherto undiscovered semantic features turn out to be relevant to ideas of central concepts. In the same way, certain aspects of an earlier decision may remain unnoticed until a new, unenvisaged situation arises. A new interpretation of Derry v Peek [1889] 14 AC 337 was proposed in Candler v Crane Christmas [1951] 2 KB 164, and finally accepted in Hedley Byrne [1963] AC 465.

In contextual semantics, the parallel with the rule of precedent is even clearer. On this view, meaning depends on shared knowledge in a given context. This tacit knowledge can only be derived from previous usage in similar situations. In his extended discussion of the contextualist debate, Recanati (Literal meaning, 2004: 143) summarises the point in this way: "The applicability of a term to novel situations depends on its similarity to the source situations. The target situation must be similar to the source situations not only with respect to the 'explicit' definition of the term, but also with respect to the hidden background. If the two situations diverge, it will be unclear whether the term will be applicable." This corresponds closely to questions regularly raised in legal argument concerning precedents.

In his theory of "Meaning Eliminativism", Recanati (2004: 146) rejects the concept of literal meaning and refers instead to "semantic potential". A similar notion is often evoked in statute construction, where meanings are often said to be "wide enough" to extend to a new use. In Julius v Oxford (Bishop) [1880] 5 AC 214, the HL had to decide the meaning of the deontic may and similar powerconferring expressions like "it shall be lawful" in the Church Discipline Act 1889. It was held that such expressions could be interpreted in particular circumstances as referring not to a power but to a duty. Yet, although the meaning of may was said to be wide enough to include the coercive sense of must or shall, the court refused to consider it as ambiguous. Such power-conferring expressions were declared to be the same "whether there is or is not a duty or obligation to use the powers which they confer." Like Recanati (2004), Lord Selbourne described the meaning as merely "potential".

Just as the law depends on interpretations decided in relevant precedents, linguistic understanding depends on shared knowledge of previous usage. In a cumulative process, new uses, like new precedents may affect the semantics of general terms. For this reason, their sense can never be fixed. In spite of the perpetual search for the Holy Grail of a determinate meaning, based on objective definition, the reference of general terms thus remains an empirical question to be decided in all the circumstances as cases arise.

\section{Dr Ross Charnock}

Maitre de Conferences at the University of Paris, specialising in the language of law 